\title{
Adsorption of thallium(I) on rutile nano-titanium dioxide and environmental implications
}

\author{
Juan Liu ${ }^{1}$, Weilong Zhang ${ }^{1}$, Yang Wu ${ }^{1}$, Haifeng Lu ${ }^{2}$, Yongheng Chen ${ }^{1}$ ， Jin Wang ${ }^{\text {Corresp., }}{ }^{1}$, Shuijing Zhai \\ Corresp.. ${ }^{3}$, Qiaohui Zhong ${ }^{1,4}$, Wanying Zhong ${ }^{1}$, Chunling Huang ${ }^{1}$, Wenhui Zhang ${ }^{1}$, Xiaoxiang Yu ${ }^{1}$, Siyu Liu \\ 1 Innovation Center and Key Laboratory of Water Quality and Conservation in the Pearl River Delta, Ministry of Education, School of Environmental Science \\ and Engineering, Guangzhou University, Guangzhou 510006, China \\ 2 Wuhan Digital Engineering Institute, Wuhan, 430205, China \\ 3 Key Laboratory of Humid Subtropical Eco-geographical Processes, Ministry of Education, College of Geography Science, Fujian Normal University, Fuzhou \\ 350007, China \\ 4 Guangzhou Institute of Geochemistry, Chinese Academy of Sciences, Guangzhou 510405, China \\ Corresponding Authors: Jin Wang, Shuijing Zhai \\ Email address: wangjin@gzhu.edu.cn, S2008shuijing@163.com
}

Rutile nano-titanium dioxide (RNTD) characterized by loose particles with diameter in 20$50 \mathrm{~nm}$ has a very large surface area for adsorption of Tl, a typical trace metal that has severe toxicity. The increasing application of RNTD and widespread discharge of TI-bearing effluents from various industrial activities would increase the risk of their co-exposure in aquatic environments. The adsorption behavior of $\mathrm{TI}(\mathrm{I})$ (a prevalent form of $\mathrm{TI}$ in nature) on RNTD was studied as a function of solution $\mathrm{pH}$, temperature, and ion strength. Adsorption isotherms, kinetics, and thermodynamics for $\mathrm{TI}(\mathrm{I})$ were also investigated. The adsorption of $\mathrm{TI}(\mathrm{I})$ on RNTD started at very low $\mathrm{pH}$ values and increased abruptly, then maintained at high level with increasing $\mathrm{pH}>9$. Uptake of $\mathrm{TI}(\mathrm{I})$ was very fast on RNTD in the first $15 \mathrm{~min}$ then slowed down. The adsorption of TI(I) on RNTD was an exothermic process; and the adsorption isotherm of $\mathrm{Tl}(\mathrm{I})$ followed the Langmuir model, with the maximum adsorption amount of $51.2 \mathrm{mg} / \mathrm{g}$ at room temperature. The kinetics of $\mathrm{Tl}$ adsorption can be described by a pseudo-second-order equation. FT-IR spectroscopy revealed that - $\mathrm{OH}$ and $-\mathrm{TiOO}-\mathrm{H}$ play an important role in the adsorption. All these results indicate that RNTD has a fast adsorption rate and excellent adsorption amount for $\mathrm{TI}(\mathrm{I})$, which can thus alter the transport, bioavailability and fate of $\mathrm{TI}(\mathrm{I})$ in aqueous environment. 
1 Adsorption of thallium(I) on rutile nano-titanium dioxide and environmental implications

2 Juan $\mathrm{Liu}^{1}$, Weilong Zhang ${ }^{1}$, Yang $\mathrm{Wu}^{1}$, Haifeng $\mathrm{Lu}^{2}$, Yongheng Chen ${ }^{1}$, Jin Wang ${ }^{1 *}$, Shuijing Zhai ${ }^{3 * *}$, Qiaohui

3 Zhong ${ }^{1,4}$, Wanying Zhong ${ }^{1}$, Chunling Huang ${ }^{1}$, Wenhui Zhang ${ }^{1}$, Xiaoxiang $\mathrm{Yu}^{1}$, Siyu Liu ${ }^{1}$

4 1. Innovation Center and Key Laboratory of Water Quality and Conservation in the Pearl River Delta, Ministry

5 of Education, School of Environmental Science and Engineering, Guangzhou University, Guangzhou

6510006 , China.

7 2. Wuhan Digital Engineering Institute, Wuhan, 430205, China.

8 3. Key Laboratory of Humid Subtropical Eco-geographical Processes, Ministry of Education, College of

$9 \quad$ Geography Science, Fujian Normal University, Fuzhou 350007, China.

4. Guangzhou Institute of Geochemistry, Chinese Academy of Sciences, Guangzhou 510405, China.

\section{Abstract}

Rutile nano-titanium dioxide (RNTD) characterized by loose particles with diameter in 20-50 nm has a very large surface area for adsorption of $\mathrm{Tl}$, a typical trace metal that has severe toxicity. The increasing application of RNTD and widespread discharge of Tl-bearing effluents from various industrial activities would increase the risk of their co-exposure in aquatic environments. The adsorption behavior of $\mathrm{Tl}(\mathrm{I})$ (a prevalent form of $\mathrm{Tl}$ in nature) on RNTD was studied as a function of solution $\mathrm{pH}$, temperature, and ion strength. Adsorption isotherms, kinetics, and thermodynamics for $\mathrm{Tl}(\mathrm{I})$ were also investigated. The adsorption of $\mathrm{Tl}(\mathrm{I})$ on RNTD started at very low pH values and increased abruptly, then maintained at high level with increasing $\mathrm{pH}>9$. Uptake of Tl(I) was very fast on RNTD in the first 15 min then slowed down. The adsorption of

${ }^{*}$ Corresponding author.

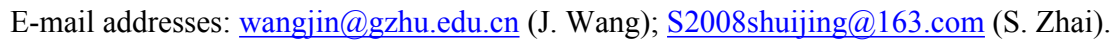


$22 \mathrm{Tl}(\mathrm{I})$ on RNTD was an exothermic process; and the adsorption isotherm of $\mathrm{Tl}(\mathrm{I})$ followed the 23 Langmuir model, with the maximum adsorption amount of $51.2 \mathrm{mg} / \mathrm{g}$ at room temperature. The 24 kinetics of $\mathrm{Tl}$ adsorption can be described by a pseudo-second-order equation. FT-IR 25 spectroscopy revealed that $-\mathrm{OH}$ and $-\mathrm{TiOO}-\mathrm{H}$ play an important role in the adsorption. All these 26 results indicate that RNTD has a fast adsorption rate and excellent adsorption amount for $\mathrm{Tl}(\mathrm{I})$, 27 which can thus alter the transport, bioavailability and fate of $\mathrm{Tl}(\mathrm{I})$ in aqueous environment.

28 Keywords: thallium; adsorption behavior; rutile nano-titanium dioxide 


\section{Introduction}

Thallium is a heavy metal whose toxicity to mammals is second only to that of methylmercury and far exceeds that of chromium, mercury, and lead ( Campanella et al., 2016; Campanella et al., 2017; Casiot et al., 2011; Galván-Arzate \& Santamaría, 1998; Grösslová et al., 2018; Li et al., 2012; Liu et al., 2016a; Perotti et al., 2017). Thallium can be accumulated in bone marrow, kidneys and different organs, thereby affecting the gastrointestinal and urinary tract, and even causing permanent damage in muscle atrophy or central nervous system (Galván-Arzate \& Santamaría, 1998; Peter \& Viraraghavan, 2005). Hence, Tl was listed as one of the toxic pollutants of priority both in USA and China (Xiao et al., 2012).

Thallium pollution is mainly due to widespread use of Tl-containing minerals in industry. For example, mining of Hg-As-Tl deposits at Lanmuchang in Guizhou, southwestern China, led to severe $\mathrm{Tl}$ poisoning in local residents during the 1960-1970s (Xiao et al., 2004a; Xiao et al., 2004b; Xiao et al., 2004c; Xiao et al., 2007; Xiao et al., 2012). Waste discharge from a Pb-Zn smelter using Tl-bearing minerals resulted in Tl pollution in the Northern Branch of the Pearl River in 2010 ( Liu et al., 2016b; Liu et al., 2017).

In recent years, rutile nano-titanium dioxide (RNTD) have been widely employed in a variety of products (eg. paints, cosmetics, optical component, biosensors and sunscreen) (Kusior et al., 2017). The rapid growth in $\mathrm{TiO}_{2}$ production and its industrial applications may result in enhanced release into the environment and exposure to human (Danielsson et al., 2018; Liu, 2005). Having large surface area, $\mathrm{TiO}_{2}$ nano-particles can alter the transport, bioavailability and fate of heavy metals by strong adsorption interactions. It is likely for $\mathrm{Tl}(\mathrm{I})$ and RNTD to encounter and co-exist in the aqueous environment. The adsorption of various heavy metals (such as $\mathrm{Pb}, \mathrm{Zn}, \mathrm{Cd}$ and $\mathrm{Cu}$ ) on RNTD has been extensively investigated, but it remains unclear for the adsorption behavior of Tl on RNTD (Jiang et al., 2014). 
55

56

57

58

59

60

61

62

63

64

65

66

67

68

69

70

RNTD. The effects of various parameters-RNTD dosage, ionic strength, $\mathrm{pH}$, time, initial concentration of $\mathrm{Tl}$, and temperature-on the adsorption behavior, as well as the adsorption isotherms, kinetics, and thermodynamics of $\mathrm{Tl}(\mathrm{I})$, were investigated.

\section{Materials and methods}

\subsection{Materials}

Analytical reagent (AR)-grade RNTD was purchased from Aladdin Reagents Co., Ltd. (Shanghai, China). Thallium(I) nitrate (99.5\%, metal basis) was purchased from Alfa Aesar, A Johnson Matthey Company. AR-grade $\mathrm{NaClO}_{4}, \mathrm{HClO}_{4}$, and $\mathrm{NaOH}$ were obtained from Guangzhou Chemical Reagent Co., Ltd. (China). All experiments were performed using Milli-Q water (Millipore Corp.).

\subsection{Batch adsorption experiments}

All the batch adsorption experiments were conducted in a rotary shaker $\left(25 \pm 0.2{ }^{\circ} \mathrm{C}, 200 \mathrm{rpm}\right)$ using a $50 \mathrm{~mL}$ PP centrifuge tube. The $\mathrm{pH}$ was adjusted to the desired value by using $0.1 \mathrm{~mol} / \mathrm{L}$ $\mathrm{HClO}_{4}$ or $\mathrm{NaOH}$. Stock solution of $\mathrm{TlNO}_{3}(100 \mathrm{mg} / \mathrm{L})$ was prepared with deionized water.

First, the influence of RNTD dosage on the adsorption of Tl(I) was studied. For this purpose, the concentration of RNTD was set in the range 0.5 to $5 \mathrm{~g} / \mathrm{L}$ at desired intervals, using $0.1 \mathrm{~mol} / \mathrm{L}$ $\mathrm{NaClO}_{4}$ as the background, to ensure constant ionic strength with $\mathrm{pH} 7.0 \pm 0.3$. To investigate the effect of ionic strength on $\mathrm{Tl}(\mathrm{I})$ adsorption, an appropriate amount of $\mathrm{NaClO}_{4}$ was added with the concentration ranging from 0.05 to $3 \mathrm{~mol} / \mathrm{L}$ at desired intervals. The influence of $\mathrm{pH}$ on $\mathrm{Tl}(\mathrm{I})$ adsorption was studied in the range of 2 to 11 . For isotherm studies, the temperature was set at $298 \mathrm{~K}, 303 \mathrm{~K}$ and $313 \mathrm{~K}$, respectively, and the initial concentration of Tl(I) varied from 0.02 to $20 \mathrm{mg} / \mathrm{L}$. The solutions obtained were filtered rapidly through a $0.45 \mathrm{~mm}$ membrane after 300 min, and $\mathrm{Tl}$ concentration was measured immediately by adsorption thermodynamics experiments. To evaluate the adsorption kinetics, samples were collected at desired intervals in 
79

80

81

82

83

84

85

86

87

88

89

90

91

92

93

94

95

96

97

98

99

100

the range of 0 to $300 \mathrm{~min}$. The concentration of Tl(I) was determined by inductively coupled plasma-mass spectrometry (ICP-MS; NexION, PerkinElmer US).

The adsorption amount and adsorption rate are calculated as follows:

$$
\text { Adsorption rate: } \alpha \%=\frac{C_{0}-C_{s}}{C_{0}} \times 100 \%
$$

Adsorption amount: $Q_{e}=\frac{\left(C_{0}-C_{S}\right) V}{m}$

Where, $\mathrm{C}_{0}$ - initial concentration $(\mathrm{mg} / \mathrm{L})$;

$\mathrm{C}_{\mathrm{s}}$ - remaining concentration of $\mathrm{Tl}$ after adsorption $(\mathrm{mg} / \mathrm{L})$;

V - solution volume $(\mathrm{L})$;

$\mathrm{m}$-total mass of adsorbent added ( $\mathrm{g})$.

\subsection{Characterization}

The morphologies of RNTD were observed by a JSM-7001F scanning electron microscopy (SEM, JOEL, Japan) integrated with an energy-dispersive X-ray spectrometer (Oxford Instruments, UK). To examine surface properties, FTIR absorption spectra of $\mathrm{TiO}_{2}$ nanomaterials were analyzed by using a Bruker (TENSOR27, Germany) FTIR spectrometer in the frequency range of $400-4000 \mathrm{~cm}^{-1}$, operating with a spectral resolution of $2 \mathrm{~cm}^{-1}$. The crystal phase of the sample was visualized by X-ray powder diffraction (XRD) using an X'Pert Pro Diffractometer (PANanalytical, The Netherlands) X-ray diffractometry operating at $100 \mathrm{kV}$ and $40 \mathrm{~mA}$, using $\mathrm{Cu}$ Ka radiation at a scan speed of $4 \% \mathrm{~min}$.

\section{3. Results and discussion}

\subsection{Effect of RNTD dosage}

The adsorption effect of adsorbent on $\mathrm{Tl}$ is due to the existence of active adsorption sites in the adsorbent. Under a constant initial $\mathrm{Tl}$ concentration, increase of the dosage of adsorbent will 
101 enhance the contact site, thereby increasing the adsorption amount of adsorbent on Tl (Shen et al., 102 2009). However, a decrease in adsorption amount with increased dosage was observed (Fig. 1), 103 and the adsorption rate increased from $55.4 \%$ to $92 \%$ as the dosage increased from 0.5 to $2.5 \mathrm{~g} / \mathrm{L}$. 104 It did not continue to rise afterwards due to further addition of the adsorbent will cause difficulty 105 in dispersion, which can hinder $\mathrm{Tl}$ adsorption. According to the literature, the mass of $\mathrm{TiO}_{2}$ 106 particles could increase the sedimentation aggregation (He \& Zhang, 2003).

107

108 109

\subsection{Effect of initial thallium concentration}

Initial concentration of $\mathrm{Tl}$ in natural systems will also influence $\mathrm{Tl}$ adsorption behavior (Zhang et al., 2017). As shown in Fig. 2, at 0.02 to $10 \mathrm{mg} / \mathrm{L}$, as the initial concentration increases, the adsorption rate shows a tendency to decrease unevenly from $70 \%$. From 10 to $20 \mathrm{mg} / \mathrm{L}$, the adsorption rate no obvious change with the initial concentration. Obviously, without changing the amount of adsorbent, if initial $\mathrm{Tl}$ concentration in the water is higher, the nano $\mathrm{TiO}_{2}$ can adsorb more $\mathrm{Tl}$. The adsorption rate no longer decreases at initial $\mathrm{Tl}$ concentration of $10 \mathrm{mg} / \mathrm{L}$. From the perspective of cost savings, the $\mathrm{Tl}$ concentration of $10 \mathrm{mg} / \mathrm{L}$ would be most suitable for adsorption by rutile nano $\mathrm{TiO}_{2}$, which deserves highest environmental benefits.

\subsection{Effect of ionic strength}

Another important factor affecting $\mathrm{Tl}(\mathrm{I})$ concentration in natural systems is ionic strength (Liu et al., 2011). As shown in Fig. 3, with an increase of $\mathrm{NaClO}_{4}$ concentration, the adsorption rate gradually increased from $33.6 \%$ to $86.7 \%$ and then tended to reach equilibrium. The adsorption of $\mathrm{Tl}$ mainly depends on the surface negative charge of the adsorbent. Increasing $\mathrm{NaClO}_{4}$ concentration is favorable for adsorption, but excessive concentrations reduce adsorption rate. When $\mathrm{NaClO}_{4}$ concentration is $>1.5 \mathrm{~mol} / \mathrm{L}$, the adsorption rate tends to become constant (Vilar et al., 2005). At this time, the adsorption increases with the increase of the ionic strength or is not sensitive to the ion concentration. It is likely that the inner surface complex (ISSC) is formed between RNTD and Tl, the chemical bond between RNTD and Tl is generally a coordination covalent bond. 
127

128

129

130

131

132

133

134

135

136

137

138

139

140

141

142

143

144

145

146

147

148

149

150

151

152

\subsection{Effect of pH}

The effect of the $\mathrm{pH}$ value of the solution on the adsorption is mainly achieved by changing the charge carried by the adsorbent and the adsorbate, thereby affecting the electrostatic interaction between the adsorbent and the adsorbate (Wu et al., 2005; Wu et al., 2004). As shown in Fig. 4, the $\mathrm{pH}$ of the solution exerted a significant role on the adsorption of $\mathrm{Tl}(\mathrm{I})$. The adsorption percentage rised from $28.9 \%$ to $60.2 \%$ when the $\mathrm{pH}$ increased from 2 to 11 . No obvious change in the adsorption occurred from $\mathrm{pH} 2$ to $\mathrm{pH} 5$. The adsorption amount increased slowly in the $\mathrm{pH}$ range from 2 to 5 , but very significantly in the $\mathrm{pH}$ range from 5 to 9 , followed by a plateau at $\mathrm{pH}$ 9 to 11 . In aqueous solution, $\mathrm{Tl}^{+}$is the predominant species in the $\mathrm{pH}$ range of $2-11$. The elevated adsorption amount with $\mathrm{pH}$ can be owing to $\mathrm{pH}_{\mathrm{pzc}}$ of the $\mathrm{RNTD}$ adsorbent (Govender et al., 2007; Mahamuni et al., 1999; Vayssieres et al., 2001). At pH values of 2 5, which are lower than $\mathrm{pH}_{\mathrm{pzc}}$, the surface charge of the RNTD was positive. It facilitated great electrostatic repulsion between $\mathrm{Tl}^{+}$and positively-charged $\mathrm{RNTD}$, which inhibited adsorption of $\mathrm{Tl}(\mathrm{I})$ ions. At $\mathrm{pH}$ values (6 9) higher than $\mathrm{pH}_{\mathrm{pzc}}$, the surface charge of the TNTs turned negative, which promoted the adsorption of $\mathrm{Tl}^{+}$, due to the electrostatic force of attraction between $\mathrm{Tl}(\mathrm{I})$ ions and the surface. For further increase in $\mathrm{pH}$, approximately $60 \%$ removal efficiency was achieved when $\mathrm{pH}$ was above 9, suggesting a fairy good adsorption performance of RNTD.

\subsection{Adsorption kinetics}

As shown in Fig. 5, the adsorption amount rapidly increased from 2.8 to $3.3 \mathrm{mg} / \mathrm{g}$ in the first 515 min but did not change significantly further on, indicating a rapid adsorption of $\mathrm{Tl}(\mathrm{I})$ by RNTD. The adsorption process was complete within $15 \mathrm{~min}$, The rapid uptake was mainly due to the large amount of active sites on the surface of the RNTD.

In order to better understand the behavior of Tl(I) adsorption and possible controlling mechanism, the kinetics experimental data were fitted with the commonly used kinetic models, such as pseudo first-order, pseudo second-order, and Elovich models (Liu et al., 2014; Pu et al., 2013).

Pseudo-first-order kinetic model equation is expressed by: 


$$
\lg \left(Q_{e}-Q_{t}\right)=\lg Q_{e}-\left(k_{1} t\right) / 2.303
$$

154

155

156

157

158

159

160

161

162

163

164

165

166

167

168

169

170

171

172

173

174

Where $Q_{e}$ is the adsorption amount $(\mathrm{mg} / \mathrm{g}) ; Q_{t}$ is the adsorption amount $(\mathrm{mg} / \mathrm{g})$ at time $\mathrm{t}$; and $k_{l}$ is the first-order adsorption rate constant $(\mathrm{g} / \mathrm{mg} \bullet \mathrm{min})$.

Pseudo-second-order kinetic model equation is expressed as follows:

$$
t / Q_{t}=1 / k_{2} Q_{e}{ }^{2}+t / Q_{e}
$$

Where $Q_{e}$ is the adsorption amount $(\mathrm{mg} / \mathrm{g}) ; Q_{t}$ is the adsorption amount $(\mathrm{mg} / \mathrm{g}) ; k_{2}$ is the secondary adsorption rate constant $(\mathrm{g} / \mathrm{mg} \bullet \mathrm{min})$.

Elovich dynamic model is expressed by:

$$
Q_{t}=k_{e} \times \ln t+C
$$

Where $Q_{t}$ is the adsorption amount $(\mathrm{mg} / \mathrm{g})$ at time $\mathrm{t} ; k_{e}$ and $C$ are constants; $\mathrm{t}$ is the adsorption time ( $\mathrm{min})$; and $k_{e}$ is related to the adsorption efficiency. The greater the $k_{e}$ value, the higher is the adsorption efficiency.

As listed in Table 1, the kinetic results are fitted by the pseudo-second-order model very well, with a high correlation coefficient $\left(R^{2}=0.9969\right)$. This suggests that the rate-controlling step for the adsorption was the initial diffusion of metal ions from the solution and their subsequent interaction with the $-\mathrm{ONa} /-\mathrm{OH}$ groups on the RNTD surface, and the subsequent interaction between the $-\mathrm{ONa} /-\mathrm{OH}$ groups of RNTD and the metal ions.

\subsection{Adsorption isotherms}

With an increase in the initial $\mathrm{Tl}(\mathrm{I})$ concentration, the adsorption rate showed a trend of decrease from $70 \%$ to $50 \%$ (Fig. 6). The lowest adsorption amount was found at the reaction temperature of $313 \mathrm{~K}$, while higher adsorption amounts were observed at lower temperatures, which indicates that the adsorption is exothermic. The adsorption amount of RNTD showed a near- 
175 linear dependent on the initial $\mathrm{Tl}$ concentration. The adsorption of $\mathrm{Tl}(\mathrm{I})$ was reduced by increase 176 of temperature. Differences between adsorption isotherm become smaller at higher temperature.

177 Langmuir and Freundlich adsorption models were used to fit the experimental data of Tl(I).

178 The equation for the Langmuir adsorption model is

$$
C_{e} / Q_{e}=C_{e} / Q_{\max +1 /\left(Q_{\max } \times b\right)}
$$

180

181

182

183

184

185

186

187

188

189

190

191

192

193

194

195

Where $Q_{e}$ is the adsorption amount (mg/g); $Q_{\max }$ is the maximum adsorption amount $(\mathrm{mg} / \mathrm{g}) ; C_{e}$ is $\mathrm{Tl}$ concentration at adsorption equilibrium $(\mathrm{mg} / \mathrm{L})$; and $\mathrm{b}$ is the adsorption equilibrium constant $(\mathrm{L} / \mathrm{mg})$.

The equation for the Freundlich adsorption model is

$$
\ln Q_{e}=\ln k+(1 / n) \ln C_{e}
$$

Where $Q_{e}$ is the adsorption amount $(\mathrm{mg} / \mathrm{g}) ; k$ and $n$ are constants; and $C_{e}$ is $\mathrm{Tl}$ concentration at adsorption equilibrium (mg/L);

\subsection{Adsorption thermodynamics}

The thermodynamic parameters provide in-depth information about the inherent energetic changes associated with adsorption. The standard enthalpy change $\left(\Delta H^{\circ}\right)$, standard entropy change $\left(\Delta S^{o}\right)$, and Gibbs free energy change $\left(\Delta G^{o}\right)$ can be calculated from the temperaturedependent adsorption data using the following equations:

$$
\Delta G=R T \ln K_{s}
$$

where $R$ is the gas constant; $K_{s}$ is the equilibrium constant; and $T$ is the absolute temperature. 
196

197

198

199

200

201

202

203

204

205

206

207

208

209

210

211

212

213

214

215

216

217

218

219

220

$\Delta H^{\circ}$ and $\Delta S^{\circ}$ were obtained from the slope and intercept of the linear plot of $\ln K_{\mathrm{s}}$ versus $1 / T$, respectively. The thermodynamic parameters calculated from Eqs. (5) to (7) are summarized in Table 2. The results showed that the adsorption amount of $\mathrm{Tl}(\mathrm{I})$ decreased with increasing temperature. The negative values of $\Delta H^{o}$ indicated that the adsorption of $\mathrm{Tl}$ was exothermic. This can be explained by the fact that the heat of adsorption of Tl(I) on RNTD exceeds the dehydration energy of the Tl(I) ions during adsorption. The negative values of $\Delta S^{o}$ showed that adsorption of $\mathrm{Tl}$ decreased the randomness of the liquid-solid system. The negative values of $\Delta G^{o}$ suggested that the adsorption of $\mathrm{Tl}$ was spontaneous.

\section{Characterization of $\mathrm{Tl}$ adsorption}

\subsection{FTIR analysis}

Fig. 7 exhibited the FTIR spectra of pure RNTD and RNTD after Tl adsorption. The peaks at $\sim 1045 \mathrm{~cm}^{-1}$ and the strong signal between $2600 \sim 3600 \mathrm{~cm}^{-1}$ were ascribed to hydroxyl bond $\mathrm{O}-\mathrm{H}$ stretching (water adsorbed on $\mathrm{TiO}_{2}$ ) (Tanzifi et al., 2018). The wide peak between 600 and 800 $\mathrm{cm}^{-1}$ corresponded to $\mathrm{Ti}-\mathrm{O}-\mathrm{Ti}$ bonds was observed at both of the spectra. The weak absorption peak at $\sim 2360 \mathrm{~cm}^{-1}$ corresponds to the stretching vibration of TiOO-H. A strong peak attributed to $\mathrm{ClO}_{4}^{-}$is seen at $1085.8 \mathrm{~cm}^{-1}$. It can be due to the ion exchange between $\mathrm{ClO}_{4}{ }^{-}$on the surface of the RNTD after addition of $\mathrm{NaClO}_{4}$. A vibration peak due to physically adsorbed water appears at $1637.5 \mathrm{~cm}^{-1}$ (Yousefzadeh et al., 2018).

\subsection{SEM and XRD analyses}

As shown in the SEM images (Fig. 8), the surface of $\mathrm{TiO}_{2}$ nano-particles before adsorption was covered by loose particles with diameter in nm, which implies a large specific surface area. After adsorption, due to the hydrophilicity of $\mathrm{TiO}_{2}$, ultrafine nanoparticles moved randomly in the aqueous phase, diffused, and spontaneously agglomerated to produce secondary particle clumping. Thus, a dispersed system of micron-sized and nano-sized $\mathrm{TiO}_{2}$ coexists in the solution, between the colloidal system and the coarsely dispersed system (Fig. 8). 
221 The XRD patterns of pure RNTD and RNTD after Tl adsorption were presented in Fig. 9. Not

222 obvious differences were observed between the two patterns. Anatase and rutile phases of

$223 \mathrm{TiO}_{2}$ were observed in both of the patterns at the $2 \theta$ angles of 27.48、36.12、39.24、41.28、

$22444.08 、 54.36 、 56.68 、 62.80 、 64.12 、 69.04 、 69.80^{\circ}$. It matched well with the standard data

225 for $\mathrm{TiO}_{2}$ diffraction pattern (JCPDS89-4920) (Maleki et al., 2016).

\section{5. Environmental implications}

227

228

229

230

231

232

233

234

235

236

237

238

239

240

241

242

243

244

245

As shown in the study, RNTD has a fast adsorption rate and excellent adsorption amount for $\mathrm{Tl}(\mathrm{I})$. It is possible that $\mathrm{Tl}(\mathrm{I})$ would release from RNTD when ingested by organisms, which may greatly increases the risk of $\mathrm{Tl}$ to the environment and organisms. In addition, RNTD may be modified differently in the environment, complicating the interaction between Tl(I) and RNTD. Moreover, the prevalence of organic matter and other heavy metal ions in aqueous environments may also contribute to the dispersion and adsorption of Tl(I) on RNTD.

\section{Conclusion}

The results showed that the $\mathrm{Tl}(\mathrm{I})$ adsorption amount of nano- $\mathrm{TiO}_{2}$ increased with increasing $\mathrm{pH}$. Efficient adsorption of $\mathrm{Tl}(\mathrm{I})$ was found to occur even at a $\mathrm{pH}$ as low as 2, whereas the optimum $\mathrm{pH}$ for $\mathrm{Tl}(\mathrm{I})$ adsorption was approximately 9-10. The adsorption was rapid, with high removal efficiency of $\mathrm{Tl}$ (I) more than $40 \%$ in the first $15 \mathrm{~min}$. The adsorption of $\mathrm{Tl}(\mathrm{I})$ on nano- $\mathrm{TiO}_{2}$ fitted well to the Langmuir isotherm, with a calculated maximum adsorption amount of 51.2 $\mathrm{mg} / \mathrm{g}$ at room temperature, indicating monolayer adsorption sites for $\mathrm{Tl}$ on the adsorbent surface. The adsoprtion was found to be an exothermic process. The pseudo-second-order equation could best fit the kinetics of $\mathrm{Tl}$ adsorption $\left(R^{2}=0.9969\right)$. All these results suggest the pivotal role of RNTD on altering the transport, bioavailability and fate of $\mathrm{Tl}(\mathrm{I})$ in aqueous environment. More works are necessary to improve the understanding of the transport and fate of nano-titanium dioxide and $\mathrm{Tl}(\mathrm{I})$. 


\section{References}

Véronique Adam, Stéphanie Loyaux-Lawniczak, \& Quaranta G. 2015. Characterization of engineered Tio 2 nanomaterials in a life cycle and risk assessments perspective. Environmental Science and Pollution Research. 22(15):11175-92 DOI 10.1007/s11356-015-4661-x.

Campanella B, Casiot C, Onor M, Perotti M, Petrini R, and Bramanti E. 2017. Thallium release from acid mine drainages: Speciation in river and tap water from Valdicastello mining district (northwest Tuscany). Talanta 171:255-261 DOI 10.1016/j.talanta.2017.05.009.

Campanella B, Onor M, D'Ulivo A, Giannecchini R, D'Orazio M, Petrini R, and Bramanti E. 2016. Human exposure to thallium through tap water: A study from Valdicastello Carducci and Pietrasanta (northern Tuscany, Italy). Science of the Total Environment 548-549:33-42 DOI 10.1016/j.scitotenv.2016.01.010.

Casiot C, Egal M, Bruneel O, Verma N, Parmentier M, and Elbazpoulichet F. 2011. Response to Comment on "Predominance of Aqueous $\mathrm{TI}(\mathrm{I})$ Species in the River System Downstream from the Abandoned Carnoulès Mine (Southern France)". Environmental Science \& Technology 45:2056-2064 DOI 10.1021/es204479k.

Danielsson K, Persson P, Gallego-Urrea JA, Abbas Z, Rosenqvist J, and Jonsson CM. 2018. Effects of the adsorption of NOM model molecules on the aggregation of $\mathrm{TiO}_{2}$ nanoparticles in aqueous suspensions. Nanoimpact 10:177-187 DOI 10.1016/j.impact.2018.05.002.

Galván-Arzate S, and Santamaría A. 1998. Thallium toxicity. Toxicol Lett 99:1-13 DOI 10.1016/S03784274(98)00126-X.

Govender K, Boyle DS, O’Brien P, Binks D, West D, and Coleman D. 2007. Room-Temperature Lasing Observed from ZnO Nanocolumns Grown by Aqueous Solution Deposition. Aiche Meeting DOI 10.1002/chin.200247008.

Grösslová Z, Vaněk A, Oborná V, Mihaljevič M, Ettler V, Trubač J, Drahota P, Penížek V, Pavlů L, and Sracek 0. 2018. Thallium contamination of desert soil in Namibia: Chemical, mineralogical and isotopic insights. Environmental Pollution 239:272-280 DOI 10.1016/j.envpol.2018.04.006.

He W, and Zhang XD. 2003. Study of the reunion control of nanocrystalline $\mathrm{TiO}_{2}$. Rare Metal Materials \& Engineering 32:816-819

Kusior A, Banas J, Trenczek-Zajac A, Zubrzycka P, Micek-Ilnicka A, and Radecka M. 2017. Structural properties of $\mathrm{TiO}_{2}$ nanomaterials. Journal of Molecular Structure 1157 DOI 10.1016/j.molstruc.2017.12.064.

Li S, Xiao TF, and Zheng B. 2012. Medical geology of arsenic, selenium and thallium in China. Science of the Total Environment 421-422:31 DOI 10.1016/j.scitotenv.2011.02.040.

Liu C. 2005. Effect of Nano- $\mathrm{TiO}_{2}$ on Strength of Naturally Aged Seeds and Growth of Spinach. Biological Trace Element Research 104:83-91 DOI 10.1385/bter:104:1:083.

Liu J, Luo X, Wang J, Xiao TF, Chen D, Sheng G, Yin ML, Lippold H, Wang C, and Chen Y. 2017. Thallium contamination in arable soils and vegetables around a steel plant-A newly-found significant source of TI pollution in South China. Environmental Pollution 224:445-453 DOI 10.1016/j.envpol.2017.02.025.

Liu J, Wang J, Chen YH, Xie X, Qi J, Lippold H, Luo D, Wang C, Su L, and He L. 2016a. Thallium transformation and partitioning during $\mathrm{Pb}-\mathrm{Zn}$ smelting and environmental implications. Environmental Pollution 212:77 DOI 10.1016/j.envpol.2016.01.046. 
Liu J, Wang J, Chen YH, Xie X, Qi J, Lippold H, Luo D, Wang C, Su L, and He L. 2016b. Thallium transformation and partitioning during $\mathrm{Pb}-\mathrm{Zn}$ smelting and environmental implications. Environmental Pollution 212:77-89 DOI 10.1016/j.envpol.2016.01.046.

Liu J, Lippold H, Wang J, Lippmann-Pipke J, and Chen YH. 2011. Sorption of thallium(I) onto geological materials: Influence of pH and humic matter. Chemosphere 82: 866-871 DOI 10.1016/j.chemosphere.2010.10.089.

Liu W, Zhang P, Alistair GLB, Chen H, and Ni JR. 2014. Adsorption mechanisms of thallium(I) and thallium(III) by titanate nanotubes: Ion-exchange and co-precipitation. Journal of Colloid and Interface Science 423: 67-75 DOI 10.1016/j.scitotenv.2011.04.008.

Mahamuni S, Borgohain K, Bendre BS, Leppert VJ, and Risbud SH. 1999. Spectroscopic and structural characterization of electrochemically grown ZnO quantum dots. Journal of Applied Physics 85:28612865 DOI 10.1063/1.369049.

Maleki A, Hayati B, Najafi F, Gharibi F, and Sang WJ. 2016. Heavy metal adsorption from industrial wastewater by PAMAM/TiO 2 nanohybrid: Preparation, characterization and adsorption studies. Journal of Molecular Liquids 224:95-104 DOI 10.1016/j.molliq.2016.09.060.

Perotti M, Petrini R, D'Orazio M, Ghezzi L, Giannecchini R, and Vezzoni S. 2017. Thallium and Other Potentially Toxic Elements in the Baccatoio Stream Catchment (Northern Tuscany, Italy) Receiving Drainages from Abandoned Mines. Mine Water \& the Environment 1-11 DOI 10.1007/s10230-0170485-x.

Peter AL, and Viraraghavan T. 2005. Thallium: a review of public health and environmental concerns. Environment International 31:493-501 DOI 10.1016/j.envint.2004.09.003.

Pu YB, Yang XF, Zheng H, Wang DS, Su Y, and He J. 2013. Adsorption and desorption of thallium(I) on multiwalled carbon nanotubes. Chemical Engineering Journal 219: 403-410 DOI https://doi.org/10.1016/j.cej.2013.01.025.

Shen YF, Tang J, Nie ZH, Wang YD, Ren Y, and Zuo L. 2009. Preparation and application of magnetic $\mathrm{Fe}_{3} \mathrm{O}_{4}$ nanoparticles for wastewater purification. Separation \& Purification Technology 68:312-319 DOI 10.1016/j.seppur.2009.05.020.

Tanzifi M, Yaraki MT, Karami M, Karimi S, Kiadehi AD, Karimipour K, and Wang S. 2018. Modelling of dye adsorption from aqueous solution on polyaniline/carboxymethyl cellulose/ $\mathrm{TiO}_{2}$ nanocomposites. Journal of Colloid \& Interface Science 519:127-133 DOI 10.1016/j.jcis.2018.02.059.

Vayssieres L, Keis K, Steneric Lindquist A, and Hagfeldt A. 2001. Purpose-Built Anisotropic Metal Oxide Material: 3D Highly Oriented Microrod Array of ZnO. Journal of Physical Chemistry B 105:3350-3352 DOI 10.1021/jp010026s.

Vilar VJP, Botelho CMS, and Rui ARB. 2005. Influence of $\mathrm{pH}$, ionic strength and temperature on lead biosorption by Gelidium and agar extraction algal waste. Process Biochemistry 40:3267-3275 DOI 10.1016/j.procbio.2005.03.023.

$\mathbf{W u ~ Z , ~ J o o ~ H , ~ a n d ~ L e e ~ K . ~ 2 0 0 5 . ~ K i n e t i c s ~ a n d ~ t h e r m o d y n a m i c s ~ o f ~ t h e ~ o r g a n i c ~ d y e ~ a d s o r p t i o n ~ o n ~ t h e ~}$ mesoporous hybrid xerogel. Chemical Engineering Journal 112:227-236 DOI 10.1016/j.cej.2005.07.011. 
324

325

326

327

328

329

330

331

332

333

334

335

336

337

338

339

340

341

342

343

344

345

346

347

348

349

350

351

352

353

354

355

356

357
Xiao TF, Guha J, Boyle D, Liu CQ, Zheng B, Wilson GC, Rouleau A, and Chen J. 2004a. Naturally occurring thallium: a hidden geoenvironmental health hazard? Environment International 30:501-507 DOI 10.1016/j.envint.2003.10.004.

Xiao TF, Guha J, Dan B, Liu CQ, and Chen J. 2004b. Environmental concerns related to high thallium levels in soils and thallium uptake by plants in southwest Guizhou, China. Science of the Total Environment 318:223 DOI 10.1016/S0048-9697(03)00448-0.

Xiao TF, Guha J, Liu CQ, Zheng B, Wilson G, Ning Z, and He L. 2007. Potential health risk in areas of high natural concentrations of thallium and importance of urine screening. Applied Geochemistry 22:919929 DOI 10.1016/j.apgeochem.2007.02.008.

Xiao TF, Yang F, Li S, Zheng B, and Ning Z. 2012. Thallium pollution in China: A geo-environmental perspective. Science of the Total Environment 421-422:51-58 DOI 10.1016/j.scitotenv.2011.04.008.

Xiao TF, Guha J, and Boyle D. 2004c. High Thallium Content in Rocks Associated with Au-As-Hg-Tl and Coal Mineralization and Its Adverse Environmental Potential in SW Guizhou, China. Geochemistryexploration Environment Analysis 4:243-252 DOI 10.1144/1467-7873/04-204.

Yousefzadeh $\mathrm{H}$, Salarian AA, and Kalal HS. 2018. Study of $\mathrm{Pb}$ (II) adsorption from aqueous solutions by $\mathrm{TiO}_{2}$ functionalized with hydroxide ethyl aniline $\left(\mathrm{PHEA} / \mathrm{n}-\mathrm{TiO}_{2}\right)$. Journal of Molecular Liquids DOI 10.1016/j.molliq.2018.03.023.

Wu ZJ, Ik-SungAhn, Lin YX, Huang LY, Lan XR, and KangtaekLee. 2004. Methyl orange adsorption by microporous and mesoporous $\mathrm{TiO}_{2}-\mathrm{SiO}_{2}$ and $\mathrm{TiO}_{2}-\mathrm{SiO}_{2}-\mathrm{Al}_{2} \mathrm{O}_{3}$ composite xerogels. Composite Interfaces 11:205-212 DOI 10.1163/156855404322971459.

Zhang GS, Fan F, Li XP, Qi JY, and Chen YH. 2017. Superior adsorption of thallium(I) on titanium peroxide: performance and mechanism. Chemical Engineering Journa/331: 471-479 DOI 10.1016/j.cej.2017.08.053.

7

8

(1)

0

1

2

53




\section{Table captions}

359 Table 1. Kinetic parameters for adsorption of $\mathrm{Tl}(\mathrm{I})$ on rutile nano- $\mathrm{TiO}_{2}$

360 Table 2. Isotherm parameters for adsorption of $\mathrm{Tl}(\mathrm{I})$ on rutile nano- $\mathrm{TiO}_{2}$

361

362 Figure captions

363 Fig. 1. Effect of rutile nano- $\mathrm{TiO}_{2}$ dosage on $\mathrm{Tl}$ adsorption

364 Fig. 2. Effect of initial concentration on adsorption of $\mathrm{Tl}$ by rutile nano- $\mathrm{TiO}_{2}$

365 Fig. 3. Effect of ionic strength on adsorption of $\mathrm{Tl}$ by rutile nano- $\mathrm{TiO}_{2}$

366 Fig. 4. Effect of $\mathrm{pH}$ on adsorption of $\mathrm{Tl}$ by rutile nano- $\mathrm{TiO}_{2}$

367 Fig. 5. Effect of time on adsorption of $\mathrm{Tl}$ by rutile nano- $\mathrm{TiO}_{2}$

368 Fig. 6. Adsorption isotherms of $\mathrm{Tl}$ on rutile nano- $\mathrm{TiO}_{2}$

369 Fig. 7. Infrared spectra of rutile nano- $\mathrm{TiO}_{2}$

370 Fig. 8. SEM images of rutile nano- $\mathrm{TiO}_{2}$ : (a) before adsorption; (b) after adsorption

371 Fig. 9. X-ray diffraction pattern of rutile nano- $\mathrm{TiO}_{2}$; (a) Before adsorption; (b) After adsorption 
Figure 1

Effect of rutile nano- $\mathrm{TiO}_{2}$ dosage on $\mathrm{Tl}$ adsorption

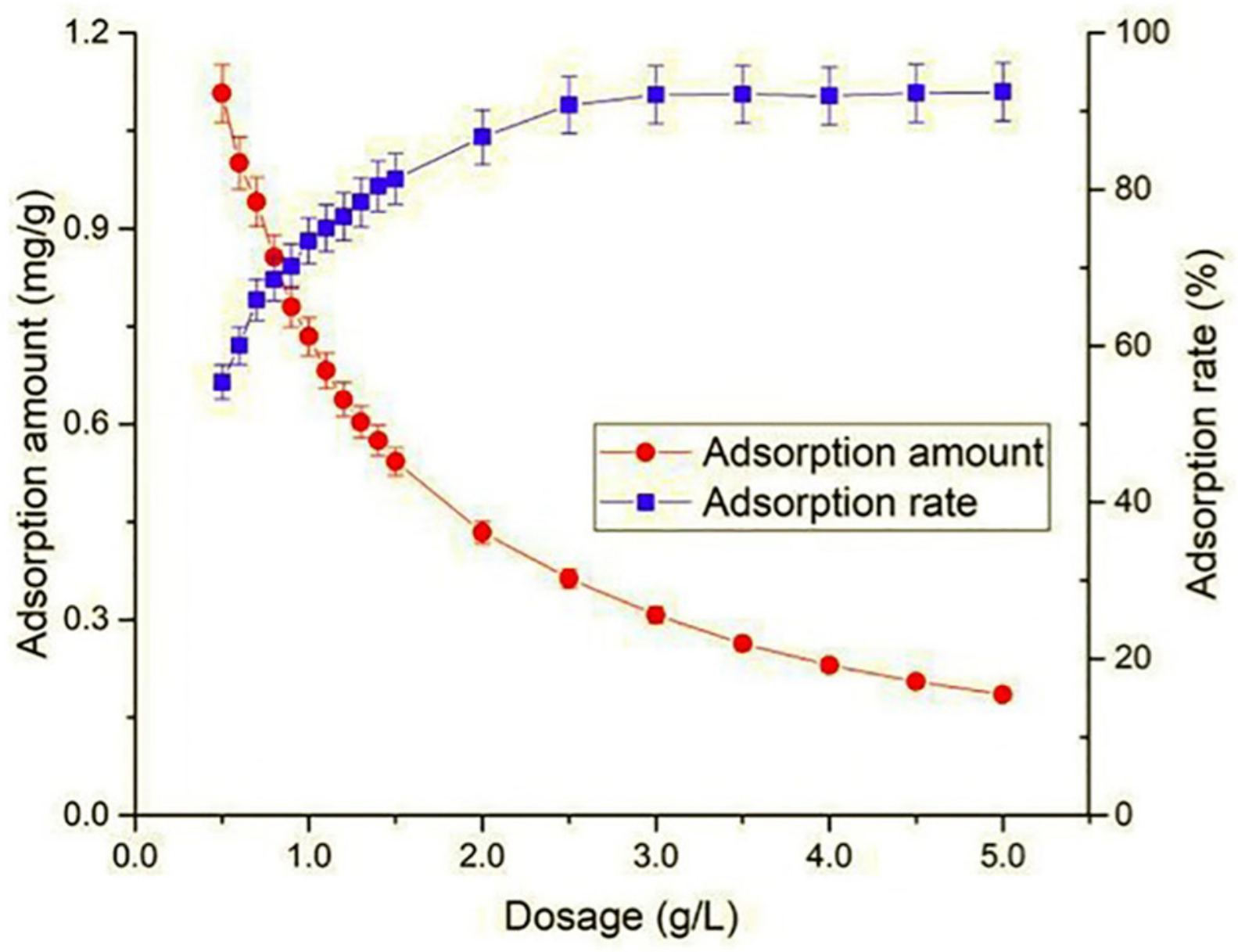


Figure 2

Effect of initial concentration on adsorption of $\mathrm{Tl}$ by rutile nano- $\mathrm{TiO}_{2}$

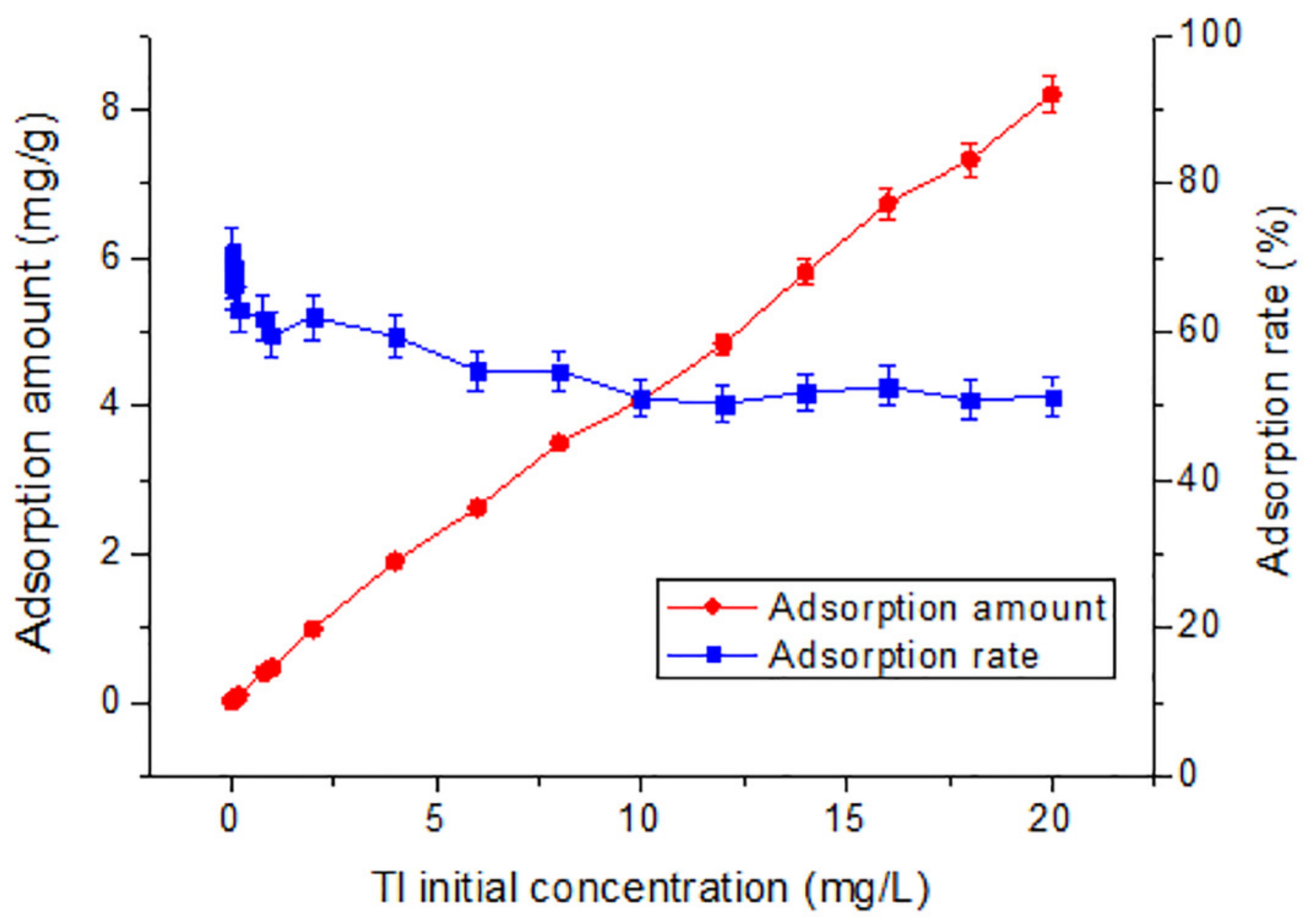


Figure 3

Effect of ionic strength on adsorption of Tl by rutile nano- $\mathrm{TiO}_{2}$

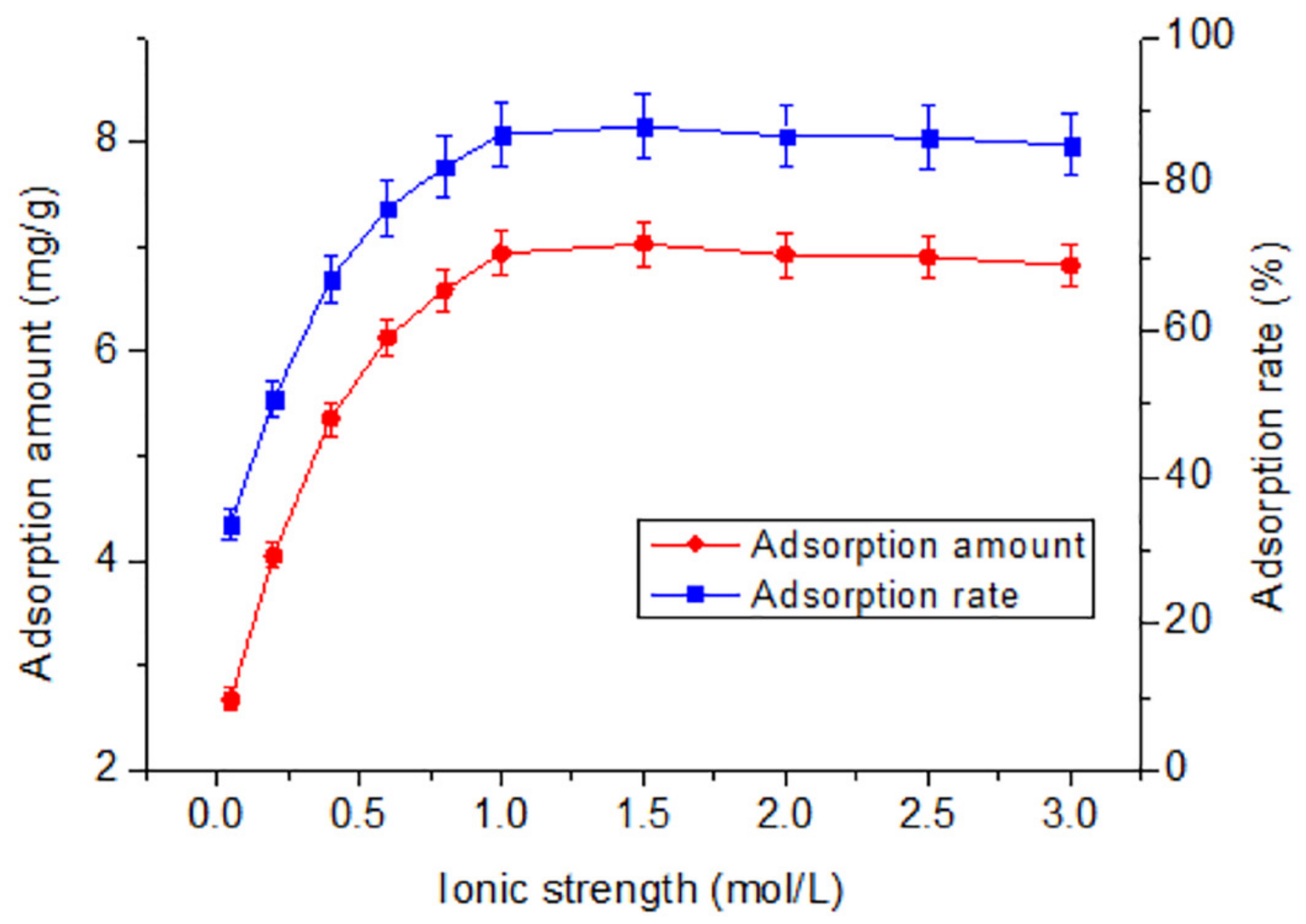


Figure 4

Effect of $\mathrm{pH}$ on adsorption of $\mathrm{Tl}$ by rutile nano- $\mathrm{TiO}_{2}$

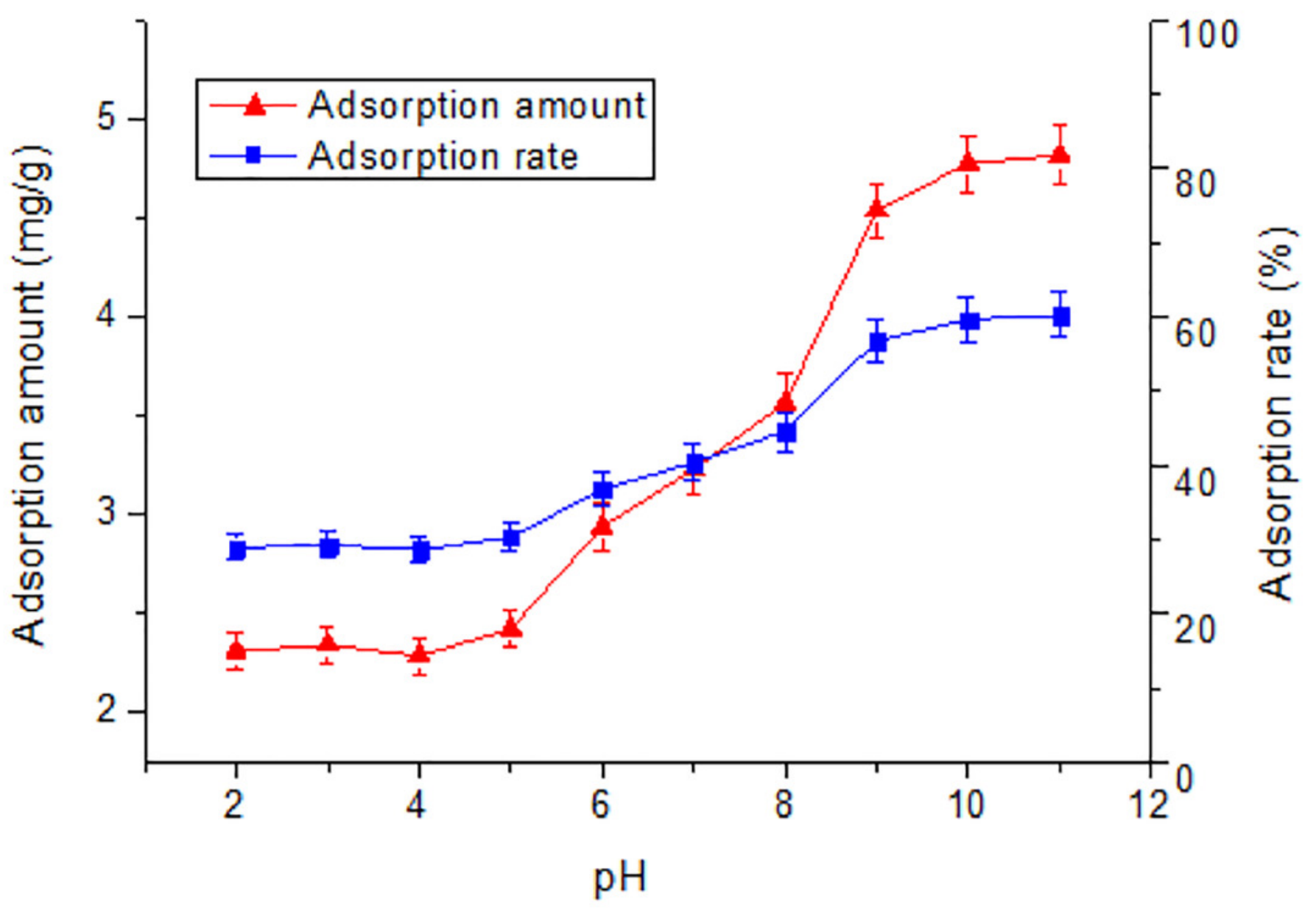


Figure 5

Effect of time on adsorption of $\mathrm{Tl}$ by rutile nano- $\mathrm{TiO}_{2}$

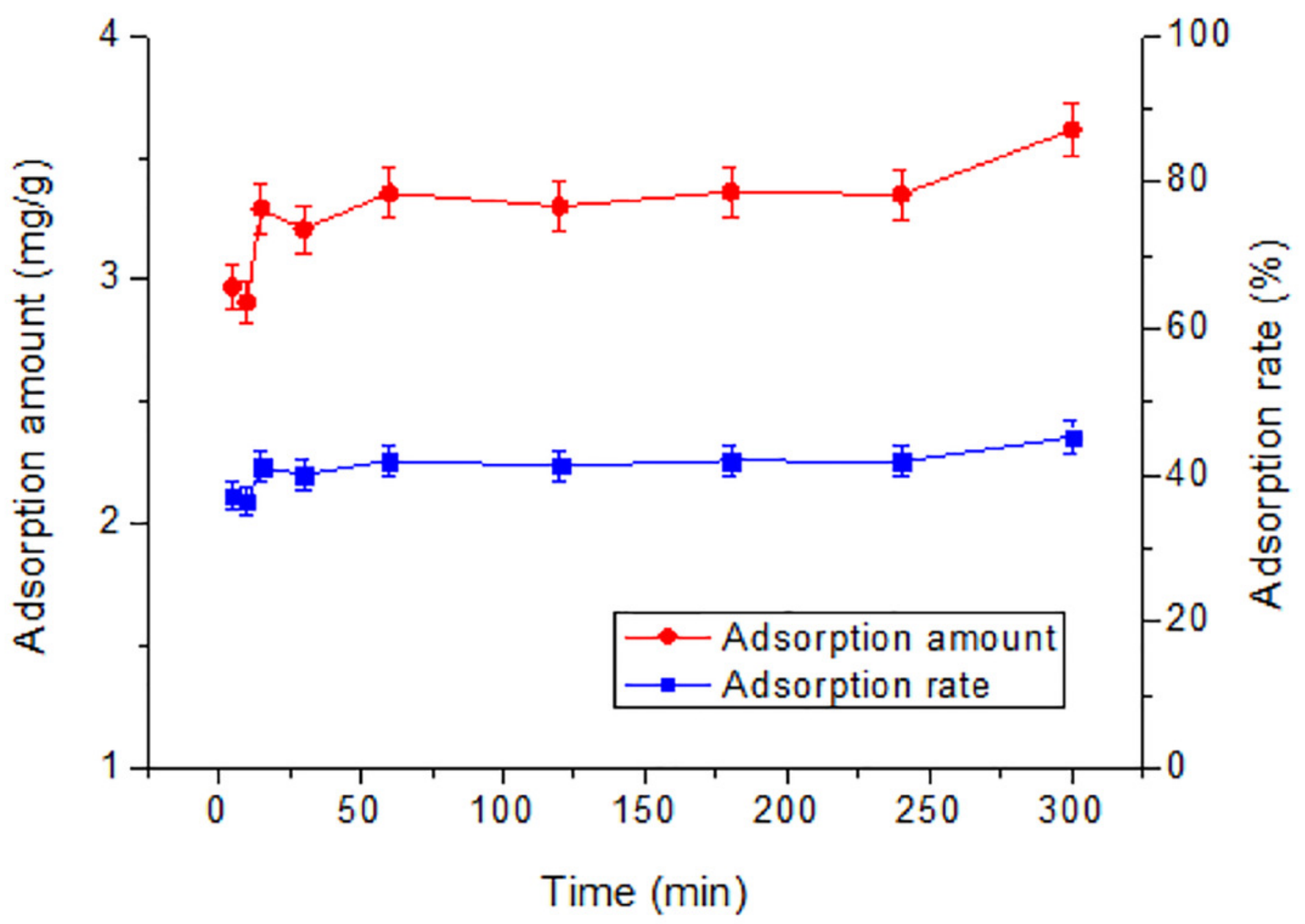


Figure 6

Adsorption isotherms of $\mathrm{Tl}$ on rutile nano- $\mathrm{TiO}_{2}$

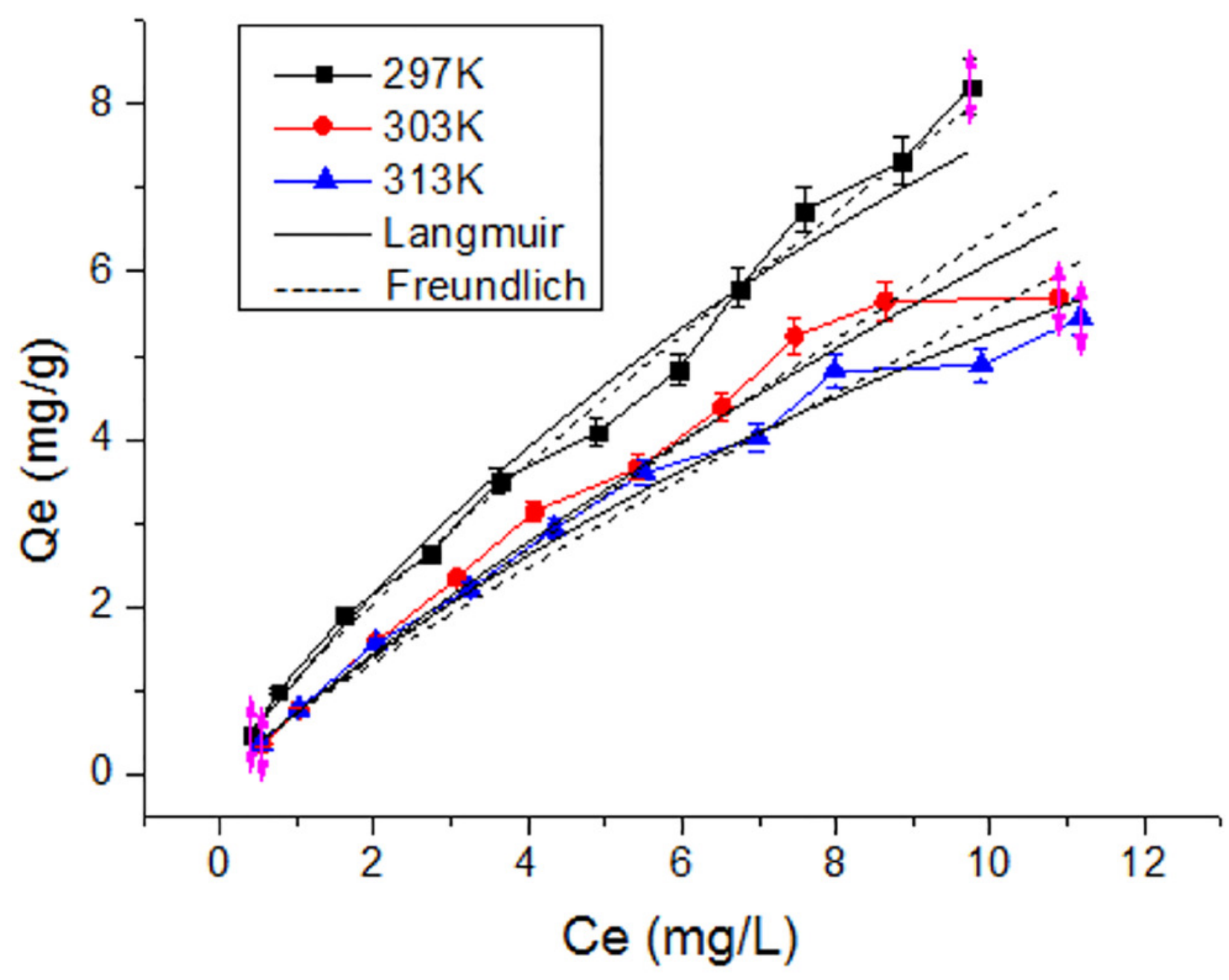


Figure 7

Infrared spectra of rutile nano- $\mathrm{TiO}_{2}$

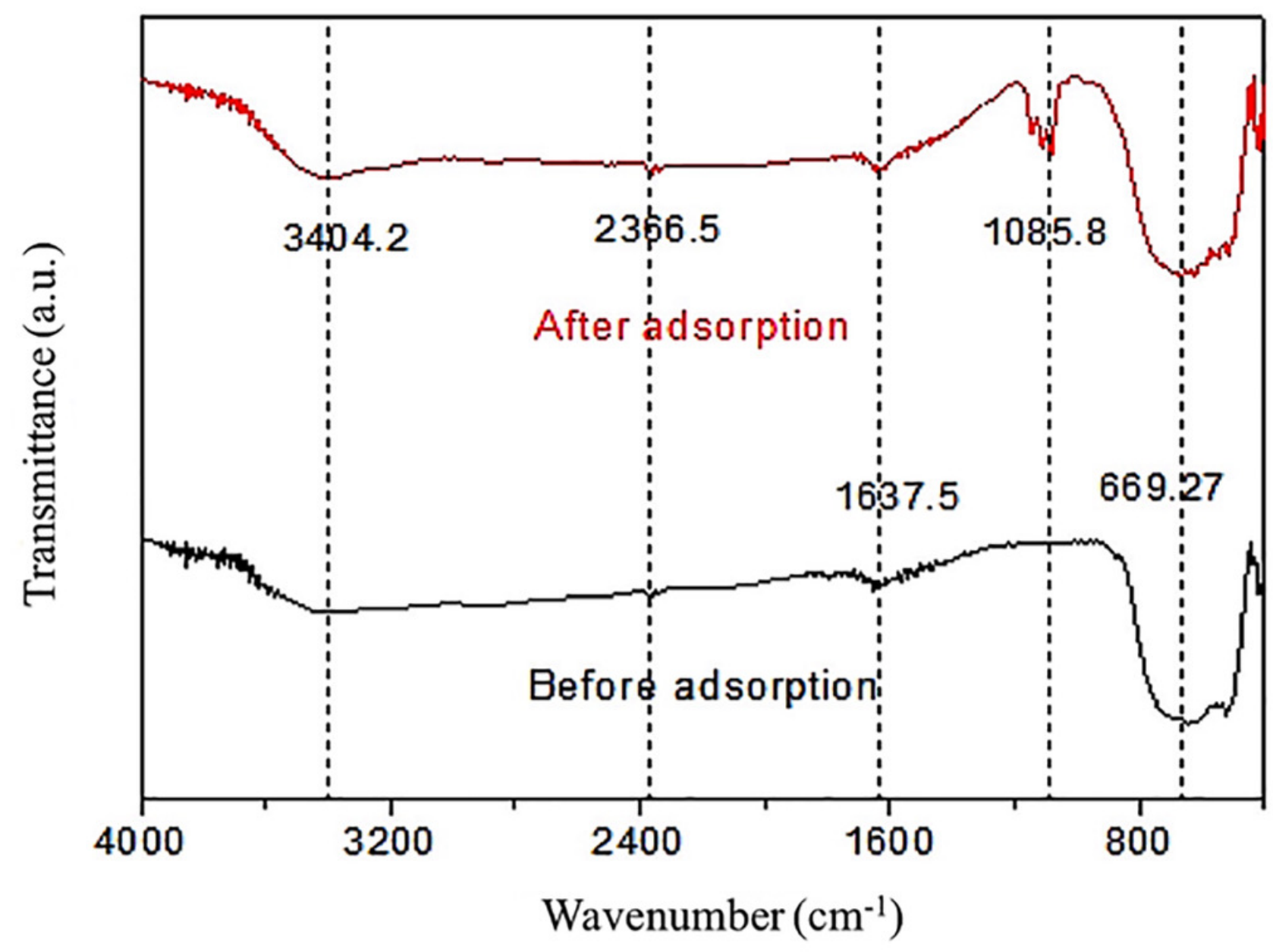




\section{Figure 8}

SEM-EDS image after adsorption of nano- $\mathrm{TiO}_{2}$; (a) Before adsorption; (b) After adsorption
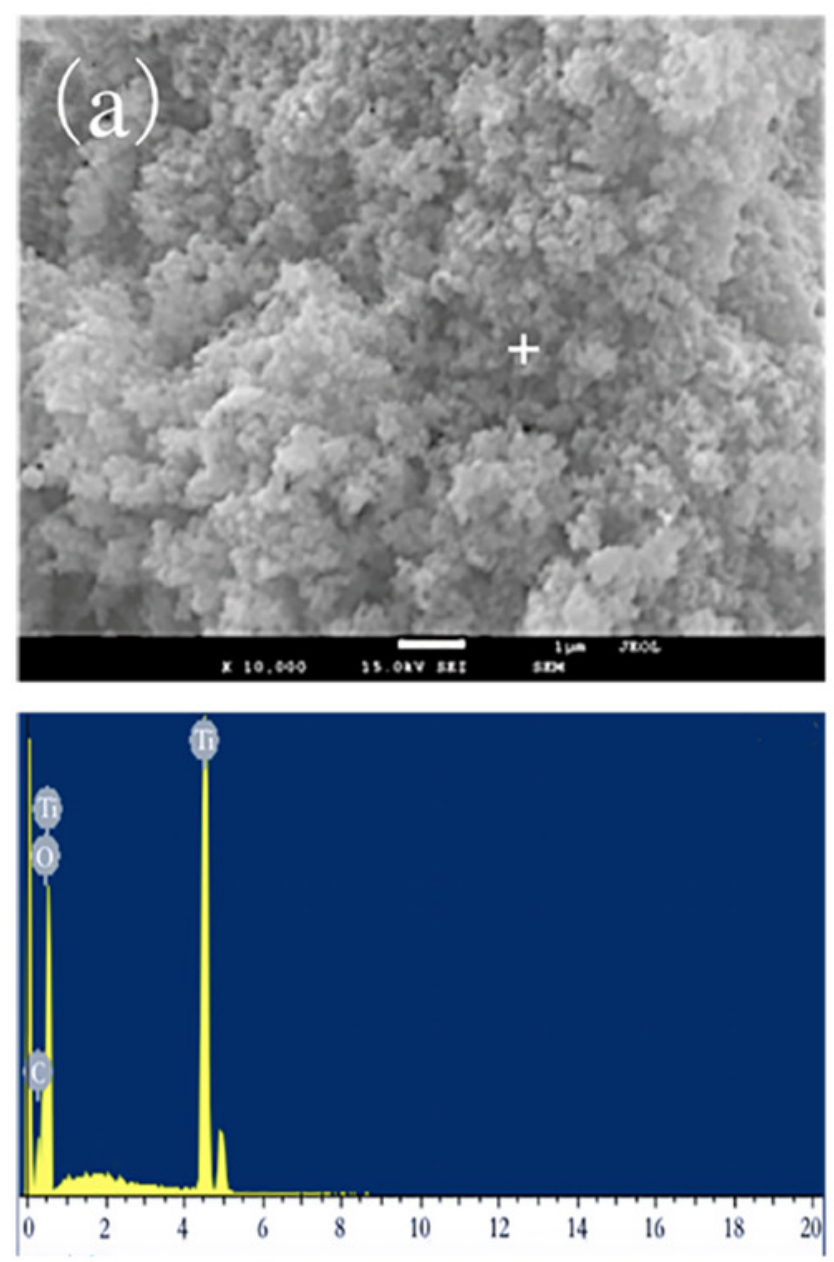
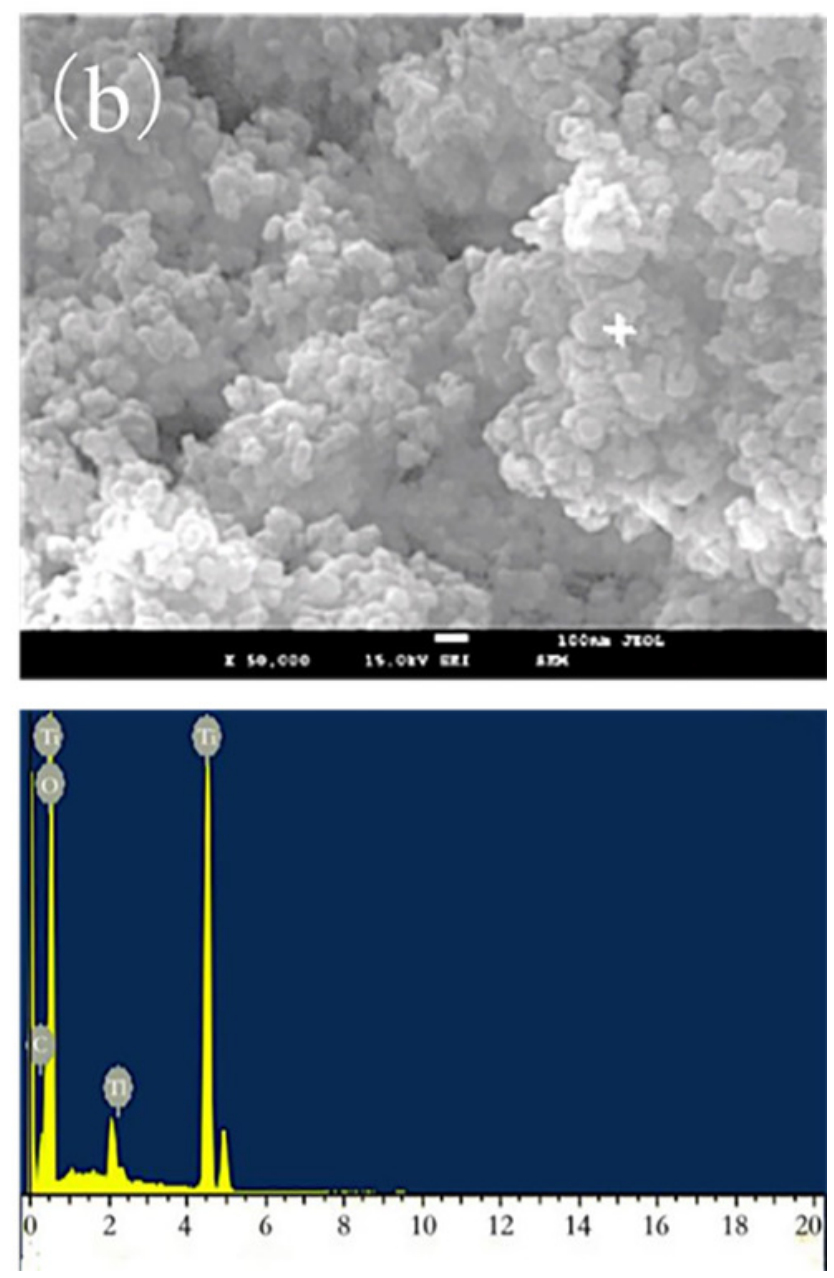
Figure 9

X-ray diffraction pattern of nano- $\mathrm{TiO}_{2}$; (a) Before adsorption; (b) After adsorption
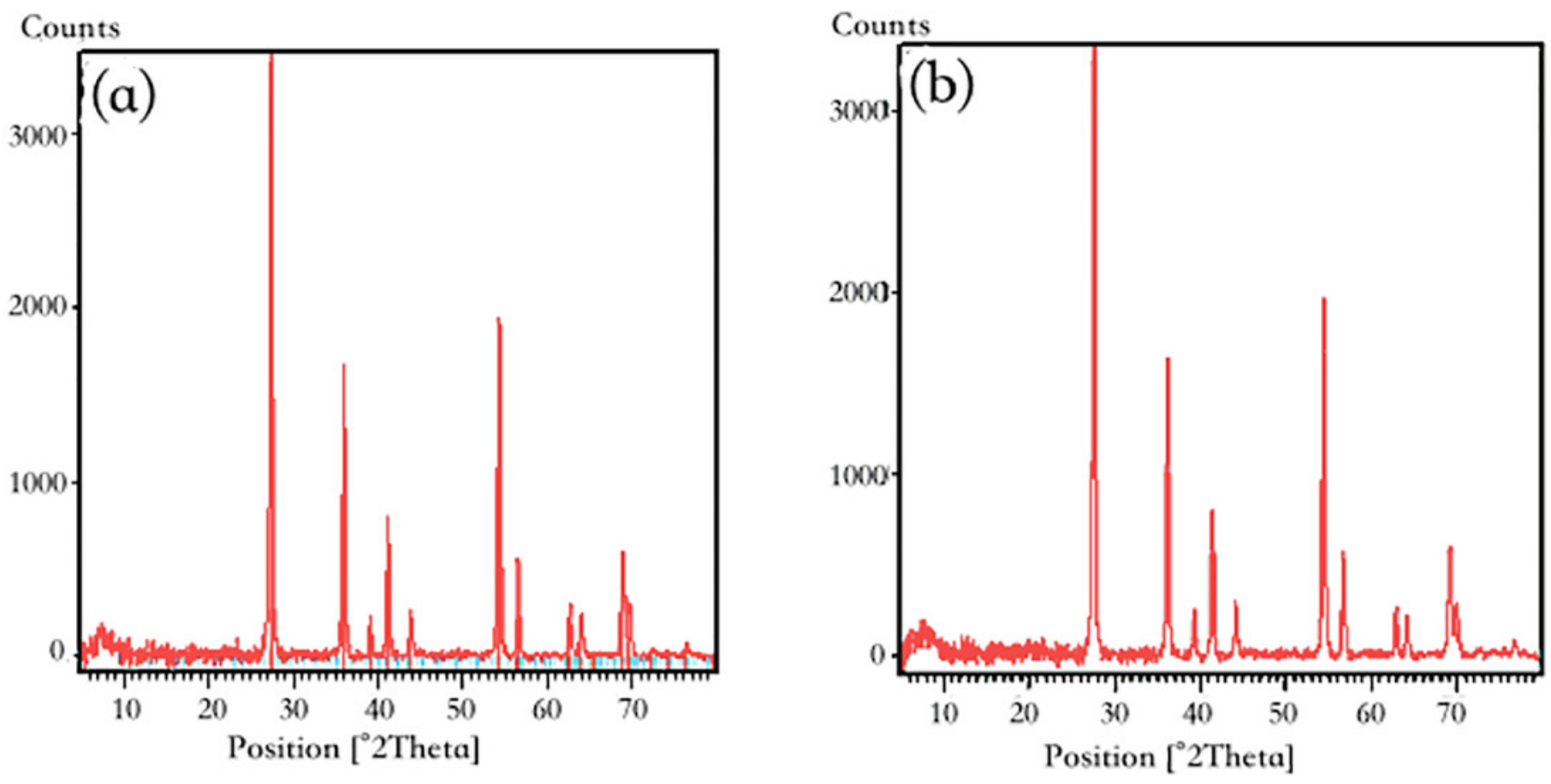


\section{Table 1 (on next page)}

Kinetic parameters for adsorption of $\mathrm{Tl}(\mathrm{I})$ on rutile nano- $\mathrm{TiO}_{2}$ 
1 Table. 1 Kinetic parameters for adsorption of $\mathrm{Tl}(\mathrm{I})$ on rutile nano- $\mathrm{TiO}_{2}$

\begin{tabular}{cccccccccc}
\hline \multicolumn{3}{c}{ Quasi-first-order } & \multicolumn{4}{c}{ Quasi-secondary } & \multicolumn{3}{c}{ Elovich } \\
$\mathrm{k}_{1}$ & $\mathrm{q}_{\mathrm{e}}$ & $\mathrm{R}^{2}$ & $\mathrm{k}_{2}$ & $\mathrm{qe}$ & $\mathrm{R}^{2}$ & $\mathrm{k}_{\mathrm{e}}$ & $\mathrm{C}$ & $\mathrm{R}^{2}$ \\
\hline 0.0014 & 3.0285 & 0.6169 & 0.0857 & 3.5157 & 0.9969 & 0.1229 & 2.7796 & 0.6947 \\
\hline
\end{tabular}

2 


\section{Table 2 (on next page)}

Isotherm parameters for adsorption of $\mathrm{Tl}(\mathrm{I})$ on rutile nano- $\mathrm{TiO}_{2}$ 
1 Table. 2 Isotherm parameters for adsorption of $\mathrm{Tl}(\mathrm{I})$ on rutile nano- $\mathrm{TiO}_{2}$

\begin{tabular}{cccc}
\hline $\mathrm{T} / \mathrm{K}$ & $\Delta \mathrm{H} /\left(\mathrm{kJ} \cdot \mathrm{mol}^{-1}\right)$ & $\Delta \mathrm{S} /\left(\mathrm{kJ} \cdot \mathrm{mol}^{-1} \mathrm{~K}^{-1}\right)$ & $\Delta \mathrm{G} /\left(\mathrm{kJ} \cdot \mathrm{mol}^{-1}\right)$ \\
\hline 298 & -2.19 & -60.67 & 0.4567 \\
303 & -2.19 & -60.67 & -0.6763 \\
313 & -2.19 & -60.67 & -0.5992 \\
\hline
\end{tabular}

2 